\title{
Nurse's Roles in Patient-Family Decision Making for Palliative Patients in Indonesia and Malaysia
}

\author{
Madihah Binti Abdullah ${ }^{1}$, Titih Huriah ${ }^{1 *}$, Arianti Arianti ${ }^{2}$, Rosnani Binti Sarkasi ${ }^{3}$ \\ ${ }^{1}$ Master of Nursing, Postgraduate Program, Universitas Muhammadiyah Yogyakarta, Bantul, Indonesia; ${ }^{2}$ School of Nursing, \\ Faculty of Medicine and Health Sciences, Universitas Muhammadiyah Yogyakarta, Bantul, Indonesia; ${ }^{3}$ Kulliyah of Nursing, \\ International Islamic University Malaysia, Selangor, Malaysia
}

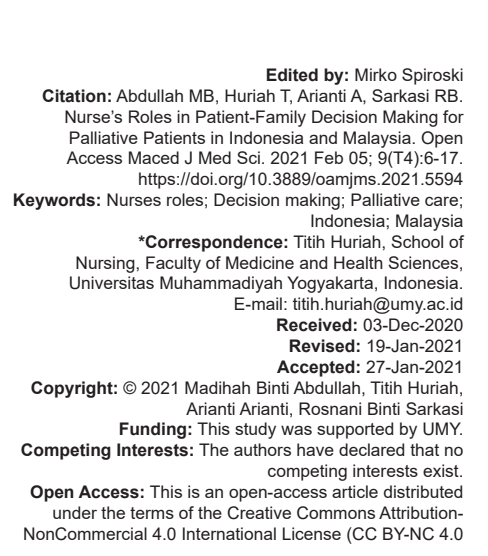

Abstract

BACKGROUND: The limited palliative care services can affect the late in palliative care management, such as late in decision making. Decision making is one of the crucial processes that every patient with life-threatening health life-limiting illness needs to overcome. Nurses can be the third party between the patients and physicians in helping them with decision making.

AIM: The aim of this study was to explore the differences perspectives of palliative care decision making for palliative patients and families in Indonesia and Malaysia.

METHODOLOGY: The study design used qualitative method with the phenomenology approach. The sample size of this study was 12 participants from two different study settings. They were three palliative nurses and three physicians from each country, selected by purposive sampling. The study was carried out at PKU Muhammadiyah Yogyakarta Hospital and Tuanku Fauziah Hospital Kangar, Perlis, Malaysia. Data collection used in-depth interview. The interpretative phenomenology analysis was used to analyze the data.

RESULTS: There were differences in the perspectives of palliative care services in Indonesia and Malaysia based on the culture form each of the countries. Nurses played a supportive role in ensuring that the care delivered to the patients and families were effective and efficient. Lack of staff was one of the challenges for Indonesia and Malaysia palliative care services need to face.

CONCLUSION: Three themes emerged from the collected data; there were views on palliative care, nurses supportive roles, and limited resources. To encounter the challenges and difficulties that interrupt the care delivery to the patients, nurses need to improve knowledge about palliative and their skills.

\section{Introduction}

The global prevalence of palliative patients increases with the increase of the aging population and the incidence of communicable and non-communicable diseases (NCDs). NCDs, including heart disease, stroke, cancer, diabetes and chronic lung disease, are collectively responsible for almost $70 \%$ of all deaths worldwide. Almost three quarters of all NCD deaths, and $82 \%$ of the 16 million people who died prematurely, or before reaching 70 years of age, occur in lowand middle-income countries [1]. For patients with age above 70 years old, the prevalence of living with cardiovascular disease increased to $53.7 \%$, while those diagnosed with neoplasm were 86.3\% [2], [3].

Both Malaysia and Indonesia also have an increase in the number of patients who receive palliative care. Malaysia recorded ischemic heart disease, which also categorized in cardiovascular diseases as the leading death cause from 2010 until 2012, with the increase in the number of accidents from $25.6 \%$ to $36.0 \%$ of deaths. Cancer, which also enlisted as the terminal health problem in need of palliative care, recorded the increase in numbers with $11.1-15.0 \%$ of the deaths [4], [5]. In 2016, HIV and AIDS also increased in incidents. Meanwhile, Indonesia also reported that non-communicable health problems increased. Stroke was the leading death cause in Indonesia since the 1990s, with the total incident increased by $61.5 \%$ and with an average of $2.7 \%$ per year. In 2016, HIV and AIDS case reports also increased from $21.5 \%$ cases to $41.2 \%$ cases [6].

Increased terminal health issues raise the need for palliative care in need. However, the facilities given are not met. Lim (2017) reported that the world palliative care alliance mapped Indonesian palliative care facilities in the third categorize, which indicated that isolated palliative care provision with palliative care growth was not well funded and limited in number compared to the size of the population [7]. Meanwhile, Malaysia was mapped in the fourth category, which denoted that palliative care services were in mainstream medicine. It had various types of palliative care services, the awareness of the healthcare professionals and communities, and the pain management services. In Malaysia, The policy had minimal impact on the services, 
availability of training, and education and had an interest in the national palliative care association concept.

Limited palliative care services can affect the late in palliative care management, such as late in decision making. Decision making is usually required in the transition of the diseases' progress to change the goals of care [8]. A systematic review conducted by Visser et al. found that 90 barriers to decision-making in palliative care were caused by physicians' lack of attitudes toward palliative patients, knowledge, practice, communication skills, and confidence their judgment of the patient's condition and prognosis [9]. Late in decision making could cause low in services' satisfaction, either for the patients, family, or healthcare practitioners [10], [11].

Decision making is one of the crucial processes that every patient with life-limiting illness health problems needs to overcome. The decision-making process is essential for them because they do not have much time to be treated with unnecessary and costly treatments. Fasten the decision making will fasten the palliative care management, which will increase the level of satisfaction [12]. Palliative care management will help in pain management, relief the sufferings, and good death holistically [13]. Promoting proper care techniques to the patients can help them have a good quality end of life, which then helps them achieve the good end of life or husnul khotimah.

Usually, patients, family, and the physician will be involved in the decision-making process, also known as shared decision making [14].However, during the process, there will be different perspectives and preferences [15]. Therefore, nurses can be the third party between the patients and physician, the family and physician, and the patient and the family in helping them for the decision making [16].

Nurses facilitate the palliative patients and family with the information about palliative informally while advocating and supporting the care [17]. However, nurses lack confidence in initiating palliative care referrals, though they know much about the patients. The lack of confidence is due to fewer opportunities given to the nurses in decision making as there are nurses-physician communication barriers [18]. The same situation also happens for palliative nurses in Malaysia and Indonesia. The nurses had been highlighted the roles in caring for the palliative patients, physically, psychologically, psychosocially, and spiritually, but not the roles of decision making [19], [20]. The aim of this study was to explore the perspectives differences of palliative care decision making for palliative patients and families in Indonesia and Malaysia.

\section{Methods}

The study was conducted in a qualitative method with the phenomenology approach. Purposive sampling was used for the participants' selection to select participants who had much experience in the study areas. The sample size of this study was 12 participants from two different study settings. They were three palliative nurses and three physicians from each setting. The selected participants were determined by including criteria (1) have been registered as nurses with more than 2 years of palliative care experience, (2) have a minimum diploma education as it is a basic nurse qualification, and (3) able to speak either Malaysian, English, or Indonesia. Meanwhile, for the exclusion criteria, the nurses did not receive any palliative care training within 6 months of working.

For physician recruitment, the inclusion criteria were (1) having experience with palliative care treatment for more than 2 years, and (2) able to speak either Malaysian, English, or Indonesia. However, the physician who did not receive any palliative care training within 6 months of working was excluded from participating in this study.

The study was carried out within May 2018 until February 2019 at two places (PKU Muhammadiyah Yogyakarta Hospital and Tuanku Fauziah Hospital Kangar, Perlis, Malaysia). The first study setting was PKU Muhammadiyah Yogyakarta Hospital (PKUMYH). $\mathrm{PKUMYH}$ is a teaching hospital that offers a higher level of routine medical care to the most complex health problems, disorders, and injuries. Furthermore, PKUMYH applies a good death concept for their patients' care management with the call of husnul khotimah concept, which is related to the palliative care goals of care.

The second study was conducted at Tuanku Fauziah Hospital, Kangar, Perlis, Malaysia. This hospital was established in 1909 by the Malaysian government to provide healthcare services to the population of Perlis. The support services include palliative care services, which are in charge of the Surgical Department. It is managed by a palliative team that consists of several physicians and nurses from various departments and other allied health departments.

The data were collected through an in-depth interview the data from the in-depth discussion were transcribed and verbatim. It was then analyzed using the interpretative phenomenology analysis that could explore what the participants did and how they understood their world as in this study how they went through their roles and responsibilities, which involved palliative care therapy. Then, using this analysis, particular facts and processes were discovered.

Approvals for this study were gained from the Ethical Committee of Universitas Muhammadiyah Yogyakarta Indonesia and Medical Research Committee (MREC) and the ethical committee of Tuanku Fauziah Hospital CRC. Verbal informed consent was obtained from the participants before the interview's date appointed, while on the day of the interview; the signed informed consent was attained. 


\section{Results}

A total of 12 participants were approached to be recruited as participants.

Table 1: The summary of each participants' details

\begin{tabular}{llll}
\hline Code & Country & Position & Level of education \\
\hline P1 & Indonesia & Residency & Degree \\
P2 & Indonesia & Consultant (Surgeon) & PhD \\
P3 & Indonesia & Specialist in Internal Medicine & Specialist \\
P4 & Indonesia & Nurse & Degree \\
P5 & Indonesia & Nurse & Degree \\
P6 & Indonesia & Nurse Manager & Degree \\
P7 & Malaysia & Residency & Degree \\
P8 & Malaysia & Residency & Degree \\
P9 & Malaysia & Residency & Degree \\
P10 & Malaysia & Nursing Supervisor & Diploma \\
P11 & Malaysia & Nurse & Diploma \\
P12 & Malaysia & Nurse & Diploma \\
\hline
\end{tabular}

All the participants agreed and interested to participate in the study. The participants were selected based on the inclusion criteria. In the first setting, RS PKU Muhammadiyah Yogyakarta, Yogyakarta Indonesia, palliative care has focused on patients with cancer and HIVIAIDS. Although there was no specific palliative team designated to run the service within this setting, palliative care management was introduced to the patients diagnosed with terminal illnesses with a life expectancy of fewer than 6 months. The service was usually introduced by the physicians in charge of the patients. Six participants agreed to participate in this study. Three participants were from the nursing department, and the other three participants were physicians from the surgical department, nephrology department, and emergency department.

Meanwhile, in the second setting, Hospital Tuanku Fauziah, Kangar, Perlis, Malaysia, palliative care has focused only on palliative patients with an advanced cancer diagnosis. The care management would be provided by the palliative team that designated explicitly to serve the palliative patients at their home. The palliative team members consisted of physicians from various departments, registered nurses, and medical assistants. The care management started once the patients had been discharged from the hospital until the patients' end of life with the patients' and family's approvals. Six participants agreed to participate in this study. Three participants were nurses, and the other three were physicians from the surgical department. All of them were the members of the palliative team from this setting.

All the nurses' participants were registered nurses with more than 2 years of experience handling palliative patients. They also had attended palliative care and other continuous nursing education to update their skills and knowledge to care and manage the palliative patients within the 6 months before the recruitment. All the physicians' participants also were involved directly in managing palliative patients for more than 2 years. They also attended many palliatives or continuous medical education to improve and upgrade their knowledge and skills, specifically in caring and managing palliative patients within the 6 months before the recruitment.

All the participants were eligible to discuss the palliative patients' decision-making process as they had their own experience with the process. They could tell what they knew, did, and understood concerning the decision-making process to the researcher, which might lead to the improvement in providing palliative care management for palliative patients specifically.

The results yielded rich descriptive summaries of the nurses' roles in decision making for the palliative patients. Three themes emerged from the collected data (Figure 1). The themes were (1) View on Palliative Care, which described the objectives of palliative referral, criteria of palliative patients, and palliative care management; (2) Nurses Play the Supportive Roles, which explains the palliative stakeholders, nursepatient relationship, and nurse-doctor relationship; (3) Limitation of resources, which illustrates the perceptions on palliative care, challenges of providing palliative care, and the future of nurses' roles.

\section{View on palliative care}

The first theme that emerged from the data was what the participants described in palliative care. This theme was described by all the participants from both countries, Indonesia and Malaysia. They explained that palliative care was not curative care management, but care management that supported the patients and their families to go through their end of life peacefully. View on palliative care was explained by the participants in several descriptions, including the objectives of palliative care referral, the inclusion and exclusion criteria of palliative care, and how palliative care management was delivered to the patients, which is different from both countries, Malaysia and Indonesia.

The study participants described the palliative referral's objectives as essential as it helped in setting the goals of care for the patients. Palliative care could improve the patients' quality end of life and live their remaining life more meaningfully.

".. the patients can spend their end of life with meaningful activities.. the patients will not just sit and wait for the death .." (P6)

".. palliative care is a way of optimizing the patients' quality end of life .." (P8)

The palliative care management could improve the quality of the patients and family at their end of life by providing the care that made their physical, emotional, social, and spiritual more comfortable to live. The physical support involved the care of patients' needs to go through their end of life without pain and could perform daily activities independently or with minimal assistance. Some of the participants said that, 
".. to help the patients to perform their daily activities independently .." (P1)

".. the palliative can ensure the patients have no pain and more comfortable end of life.." (P8)

For the emotional, spiritual, and social status of the patients, nurses were being cared to help them continuously feel motivated and encouraged while living their end of life meaningfully. Therefore, they could have a good death in the end as they wished.

".. the final goal of our care is husnulkhotimah.." (P2)

".. providing emotional support to the patients as they know about their condition .." (P12)

Palliative care is not only beneficial to the patients and family but also beneficial to healthcare services. One of the participants stated that palliative care could help regulate the quality and cost of services to the life-threatening patient because the patients only received the treatments that could support them to continue their end of life, which was much cheaper than the curative treatment.

“.. for quality control and cost control ... terminal illnesses ... which are no longer possible cured .. they want to die while being accompanied by family .. if they are without palliative care .. they will die in the hospital .. intensive care room ... which cannot be accompanied by family .." (P6)

As the participants described the palliative referral's objectives, they also listed down on the criteria that suited the palliative patients. Both of the countries, Malaysia and Indonesia participants stated that the criteria for palliative care management were for the life-limiting illness patients who could not be cured of the illnesses and had a low life expectancy.

".. The patients have been diagnosed with the terminal illness who cannot be cured.." (P6)

However, in Malaysia, the criteria were specified to the cancer patients with an advanced level of cancer and had been dependently in performing their daily living activities. Other than that the patient's house location was also considered one of the criteria that enabled them to receive the palliative care home visit.

".. If the patients able to perform $A D L$ independently even they have been diagnosed with stage 4, they can come for the appointment ..the patients will be referred again to the palliative care management once their symptoms have shown .." (P9)

Then, the participants also explained how palliative care had been managed. It was different in how Indonesian palliative care was conducted compared to the Malaysian. In Indonesia, it was hospital-based services, while Malaysia the palliative care was a home visit services. Even care management was quite different; the objectives of palliative care were still the same for both countries.

In Indonesia, palliative care was introduced to patients at the beginning of the diagnosis of terminal illnesses to increase their spiritual status. It is because religions can make the patients able to have more strength to face the illness and upcoming pains uncomfortable suffering. Furthermore, they can live their end of life more meaningfully and peacefully to prepare for a good death. One of the participants stated that,

".. husnulkhotimah cannot be achieved if it is forced. It needs to be started at the very beginning. It is late when the patients are at the terminal and comatose state. Only religion makes sufferings sufferable .." (P2)

As palliative care was introduced early for the patients, there was enough time for the patients to have discussions with their family, consult with healthcare providers such as doctors and nurses, and browse the positive and negative effects of each of their decisions. Thus, the decision that they made later would not make them regret and dissatisfy at the end of their life.

".. the patients had been given the opportunity to think and discuss with the family. The patients can consult with the nurses. The patients have been given the opportunity to browse from the internet. The nurses will not disassemble the truth from the patients..." (P4)

Meanwhile, in Malaysia, palliative care management started after receiving a referral from the specialist who in charge of the patients. Most of the referrals were from the oncologists who diagnosed the patients with illnesses. As mentioned above, the patients that were being planned to receive palliative care were those who had been diagnosed with lifethreatening and terminal illnesses, could not be cured medically anymore, and had a short life expectancy. The diagnosis should be confirmed through a CT scan and biopsy.

".. the palliative care decision making is more for the clinical condition of the patients, which has been proved by the patients' investigation result, vitals, symptoms, and complaints .." (P8)

The palliative care team would then visit the patients and reassessed the patients' health condition, house location, and surroundings. This reassessment was to ensure, the patients were really eligible for the palliative care management of home visits.

".. the patients need to be observed and assessed because some of the patients may result really in pain, but same still can bear the pain.." (P7)

".. if the patients can still walk, the appointment once for every 3 months will be given. However, if it is impossible for the patients, an early home visit will be arranged .." (P7) 
After that, the patients would be tagged with either red, yellow, or green tag. This tag helped prevent any missing patients for the visit because it represented the severity of the patients' symptoms, health status, and the frequency of visits that they needed along their end of life.

"..the referral cases will be sorted by coded color which is red (once every month) for the patients with wound dressing, yellow (once for every 2 months) for more stable patients and green (once for every 3 months) for the most the stable patients.."(P8)

".. the palliative care still visits based on the priority. While doing the visit for the old case, there will be an arrangement of visit for the new referral case .." (P11)

Even the patients had been scheduled for a visit, and they still could be rearranged based on their conditions. If there was any problem with the patients within the gap of the visit, they could contact the palliative team to consult about the problem. If there were a need for the rearrangement of the visit, they would make it earlier. For example, one participant stated that the problem was not from the patient themselves but from the caretaker who tried to commit suicide because she could not accept the patients' condition.

“.. recently, the doctor asks for the visit to be earlier as the patients' daughter try to commit suicide as she feels stress with the burden of the care .." (P12)

Some cases could not be solved at the patients' homes, so the patients would advise being admitted for further treatment to stabilize their condition. The palliative patients had a special treatment that they have been given an open admission card so that they would not have to pass the casualty for admission. The time to be admitted had been shortened so that they did not have to wait for a long time to receive the treatment.

".. The doctor will provide one paper for open admission so the patient can come anytime. Thus, the patients only need to bring that paper and directly being admitted .." (P7)

Although both countries had differences in how palliative care was managed, the goals of care are still the same. Both countries, Indonesia and Malaysia, want their palliative patients to have more meaningful and peaceful at the end of their life. They want the patients to feel comfort and peace even they have a low life expectancy and need to face the suffering of pain throughout their end of life.

\section{Nurses play supportive roles}

A major contributing factor, whether palliative care services success or not, is related to the roles played by nurses who have the closest relationship with the patients as healthcare professionals. Nurses play major roles in ensuring the delivered palliative care is effective to the patients and family.

Participants had listed down the members of the palliative stakeholders. Nurses are one of the palliative care stakeholders. The other members of the stakeholders are patients, their families, doctors in charge of the patients (consultants, specialty registrars, and foundation doctors), and other support healthcare professionals such as pharmacists, physiotherapists, dietitians, social welfare-officers, and religions officers.

".. the palliative organization consists of doctors and paramedic from multidiscipline which are from every unit and departments such as a chief nurse, nurse managers, physiotherapists, pharmacists, nurses, and medical assistants .." (P9)

The participants explained that every palliative stakeholder had responsibilities in planning and performing the care to the patients. However, the ones responsible for making the decision were the patients, family, and doctors in charge.

".. the doctors will make a decision with the palliative patients as the main decision-maker. Nevertheless, the family's opinion on the decision will be considered too. The patients will be treated as palliative patients when the family also agrees. However, if the patients refuse to be treated, it will be considered as the final decision for the palliative care management .." (P7)

As described above, nurses were not able to make a decision together with the patients and doctors. Participants agreed that nurses played the roles of professionals that supported doctors' workload. The supportive roles that were explained by participants could be divided into two interactions: (1) Nurse-patient relationship and (2) nurse-doctor relationship. Within these explanations, the nurses have shown to play supportive roles yet crucial in palliative care services.

In the nurse-doctor relationship, several roles were described by the participants to show how nurses being a supporter of the palliative patients in decision making. Nurses had been portrayed in four categories: (1) Care provider, (2) educator, (3) facilitator, and (4) advocator. These were the nurses' characteristics that helped them to care for the patients holistically.

First, as the care provider, it means literally a person who provides prevention, cure, promotion, and rehabilitation of healthcare, either to individual or group of humans. Participants explained that nurses were the care provider of the patients in the providing the palliative care with the goals of preventing the patients from pain and sufferings, curing any of the symptoms shown within them, promoting comfort for them, and encouraging for the rehabilitation so that they could perform their daily living activities independently. 
Therefore, the patients thought wisely while participating in the decision-making process.

\section{".. nurses are the supporter. Nurses support doctors by performing the doctors'orders, such as dressing. Before the home visit, doctors will give orders, and nurses will prepare for the procedures. Nurses are good enough to accomplish their responsibilities. When the patients need the dressing, the nurses will prepare the dressing equipment before the home visit based on the doctor's order." (P8)}

Then, the second category is as an educator. Educator means that a person who provides instruction or education which always refer to a teacher. Therefore, participants had explained that nurses were the one that would always give the patients and family the information of their condition and updates of any examinations taken while educating them on how to care themselves at home. Doctors had limited time with the patients, so the role in explaining and educating in detail was given for nurses to accomplish it. Thus, the patients and family had enough information that helped them to make a wise decision.

".. education can make the patients and family cooperate. Nurses will focus on educating and motivating patients. Nurses will always inform the patients, even giving the blood transfusion. During family therapy, the nurse will educate the patients and family." (P5)

The third category is the facilitator, meaning a person who makes a process easier. Thus, the participants explained the facilitator's character fit the nurses as they facilitated the patients and family to spend their end of life easier, especially in practicing their religions and making a decision of the treatment.

".. nurses should assist the patients to go in peace. Nurses can let the patients' family be near the patients while reading the Yassin or teach syahadah. These are how nurses' practice here. Nurses should not disturb the patient with a procedure that cannot help them. It is better to help them to go peacefully .." (P10)

Then, the last category, advocator, represents the meaning of a person who publicly supports or recommends a particular cause or policy. Within the conducted interviews, participants explained that nurses were active in supporting and advocating the patients and family. Even no treatment could cure their illness anymore, and they should not give up. Thus, nurses always motivated and encouraged them to live meaningfully at their end of life to have a peaceful end of life.

".. nurses will suggest the patients do the activities that will make them content and happy. Nurses will always give support to the patients to prevent them from giving up." (P4)
Therefore, to be able to advocate, motivate, and encourage the patients, nurses should have good communication skills to build rapport and trust relationships with the patients. Then, nurses would be able to explore the patients' problems, either from illnesses or their surroundings. It showed how nurses could assess the patients thoroughly.

".. nurses with soft skill in communication had the ability to ask for any sensitive problems. Nurses should not ask in the future. Thus, nurses need to note down and report so that will not be repeated because it is a sensitive issue for the patients can degrade their emotions .." (P11)

From the characteristic described by the participants about the interaction between nurses and patients, nurses helped the patients in the process of making a decision by providing appropriate care so that they were always in comfort, educating them on their condition and how to take care in the absence of nurses, facilitating them to perform their activities of daily living, and supporting while encouraging them to fulfill their end of life with meaningful activities that could make them happy, content, and peace.

While in the relationship between nurses and doctors, four categories also represented the description of participants about nurses' roles in palliative care services. The categories were (1) informant, (2) coordinator, (3) advisor, and (4) executor. Within these categories, the role of nurses helped to provide care management efficiently and effectively.

The first category is the informant. An informant means a person who gives information to others. As its literal meaning, participants explained that nurses reported about any of the patients' complaints and information to the doctors. Therefore, doctors could think about appropriate care management for the patients, especially in encountering the patients' health problems.

".. nurses should inform the patients any new information to them. Nurses have limitations in their job scope so that they will collaborate with other healthcare professionals. Nurses who observe the patients $24 \mathrm{~h}$ should inform the observation result while doctors give orders .." (P5)

Then, the second category, coordinator, represents the literal meaning of a person who organizes events or activities and negotiates with others to ensure they work together effectively. Participants explained that nurses were good at coordinating the palliative team. Even though the decision-makers were not them, they helped ensure all the team members received the same information and performed their responsibilities efficiently.

".. nurses will arrange the patients and inform the arrangement to the doctors. Nurses will 
help to coordinate the patients during the discharge. Paramedics help the doctors in coordinating the patients .." (P9)

The advisor is the third category of nurses' roles described by the participants. The advisor means that a person who gives advice and suggestion in a particular field. Participants portrayed the nurses as professionals eligible who still could give advice and suggestion even they would not be involved in the decision making. It was when the discussion happened between the healthcare providers, which showed the teamwork.

“.. standard operating procedure (SOP) will lead the team for teamwork. Every hospital will have its SOP, which is based on the viability of doctors, patients, and nurses .." (P2)

Finally, the fourth category, executor, means the doer of an action. Therefore, participants described nurses who did and performed all the orders given by the doctors. They had the skills that even doctors acknowledged it. Hence, nurses supported the palliative team by executing all the procedures planned for the patients competently and effectively.

".. for the worsening case, nurses will make a visit to check for the wound if there is any slough, smelly. Then, nurses will discuss with the doctors. Nurses will check the patient's data, such as their address and fill up the referral form, which then needs to be signed by the doctors before informing the nurses in charge of the nearest clinic .." (P12)

The nurses' roles described by the participants through the nurse-doctor relationship revealed the characteristics of nurses in helping the palliative team, especially the doctors, in making decisions. They might not directly be involved in the decision making, but indirectly they contributed in the process too as they provided the information about the patient, coordinated the doctor with the patients and other healthcare providers if when the collaboration was needed, provided advice and suggestion to the doctors regarding the treatment that suited the patients' condition and obeyed all the doctors' orders efficiently and effectively.

\section{Limitation of resources}

The last theme that emerged from the collected data is the limitation of resources. This theme represents the participants' description of palliative care services' perception, the matter that makes palliative care services challenging, and the function of nurses that can be improved in the future. These subthemes can be developed to expand the functionality of palliative care services to be better.

Participants described two perceptions of palliative care. The patients and family either could accept or follow the care management gracefully or not, which indirectly revealed that the perceptions were based on the culture of the setting. It was because all the participants from Indonesia explained that the patients and families in Indonesia had negative perspectives on palliative care management. They thought that palliative care was hopeless care management, which contradicted the belief that they could try as hard as possible.

“.. the patients' family understanding of patients' condition can be a challenge. Some of the family members have accepted it, but some cannot accept it. Some cases may end up in resuscitation to the patients who only prolong the stay at the hospital without any goals of curing .." (P1)

While the participants from Malaysia explained that the patients and family had a good and positive response once the palliative care being introduced to them, they could accept that palliative care was not hopeless care management but care that helped them to have hope that allowed them to enjoy their end of life to the fullest.

".. usually, the families will support. There is no problem with that because once the patients had been confirmed with stage 4 diagnosis, and they see the patient cannot be done much anymore. For example, patients have undergone surgery or chemotherapy, but their condition still does not improve. Therefore, when the doctor is certified the patients as palliative patients, which entitle for home treatment and a home visit, the family usually will be really supportive. The patients are usually very grateful because there is a palliative team that can help them continue their medication, nursing care, changing all the things, so, usually, there are no problems, and they will be very supportive." (P9)

The difference in how the patients and family from Indonesia and Malaysia viewed palliative care services might be because of the difference in how the services were being managed. As in Indonesia, the services were at the hospital, while in Malaysia, the services were provided within the patients' homes.

In managing palliative care services, there will be difficulties that make the delivery of care may be interrupted, which challenges the palliative care team. Most participants acknowledged that delivering palliative care to life-threatening patients was very challenging to their physical and emotional. Participants described that the challenges might come from either the patients, family, or policy. As the management of palliative care services is different between Indonesia and Malaysia, the challenges also a bit different.

For Indonesia, palliative care is challenging when the patients trust the communities more than 
healthcare professionals. Two participants described that negative prior knowledge about the treatment might affect their view on what actually palliative care actually is. Thus, nurses need to repeatedly explain and educate them so that they have hope to continue their end of life peacefully.

".. the patients feel to give up in the middle of the journey. Nurses need to re-educate and support patients." (P4)

Other than that, participants also explained the policy that had been made for palliative patients, which left them without any options to choose their preferred treatment. They needed to either follow the policy or had to uphold the consequences by themselves.

".. In BPJS policy, there is a guideline, and if the patient refuses to be referred, the patient will be considered as an APS patient which agree to pay for the treatment by themselves .." (P5)

Participants also described the Indonesian culture, which was better to die at the hospital as it represented they were trying as hard as possible to seek a cure for their diseases. The patients usually preferred to be treated at the hospital; even it was only for pain management. It is challenging for ward occupancy.

".. most patients said that in Islam, we should try as hard as we can, so the patients choose to be treated until death. Thus, even nurses offer to provide analgesia, the patients will refuse, and they preferred to be treated at the hospital as it is the reality in Indonesia .." (P6)

Meanwhile, Malaysian palliative care services are mostly within home care management. Participants described the challenges of being a lack of equipment to diagnose the actual cause of the symptoms shown by the patients. One of the examples given by the participant was difficult to breathe.

".. some of the investigations cannot be done during the home visit, which requires the patients to be mobilized to the hospital so that they can be x-rayed. For example, if the patient has a pleural effusion, it can be drained at the hospital, which cannot be conducted at home .." (P7)

Other than the lack of equipment, participants described the difficulty of finding the patient's house. The houses that were far away from the hospital were one of the including criteria of palliative care referral. Therefore, one of the participants stated that it was challenging to find the patients' house remotely located.

".. the challenge for the home visit management is finding some of the patients' house, which locates in the remote area. Some houses cannot be found because the road is small, and there will be a village behind that. Thus, it is very difficult to find the house.." (P8)
Lack of staff was also one of the challenges that Malaysian palliative care services needed to face. It was because palliative care services were run by the voluntary staff. They still had their permanent job scope at their department. Therefore, the rotation for a visit was very short, which might also affect the home visit schedule, leading to the patients' care management.

".. palliative care team had short of staff. When there is a new referred case, the team will plan to go the next week, but it cannot happen because there are many more cases that need to be visited. Thus, sometimes, the team cannot make it because there are too many patients that are referred .." (P12)

One participant described that she had difficulties in explaining to the patients with a different belief. It was a challenge for her as other religions would not understand the concept of Qadha and Qadar, so they might want to continue the curative treatment even the doctors had been suggested palliative care management, which only in the form of supportive care management.

".. all the patients have different religions in which some beliefs are in other religions, so their goals are trying to save, help, and cure the patients. Like the Muslim, the palliative team also tries to help, but with the integration of Islam. Thus, the patients will try to understand that this is His plan, Qadha, and Qadar. It is different from other believers which is a bit difficult to explain it.." (P10)

To encounter the challenges and difficulties that interrupted the delivery of care to the patients, participants suggested several things that nurses need to improve so that the better palliative care management can be served to the community. Most suggestions acquired nurses to improve their knowledge about palliative and their skills. Knowledgeable and skillful nurses could ensure the palliative care services for both countries Indonesia and Malaysia improve for the better.

".. For nurses to make a decision, first, they should have post-basic in palliative. If it is from normal nurses, when the nurses give a suggestion to the doctors, such as informing them that the patient is dying so the patient should be stopped from any of the curative treatments, it will not be right. If the nurses have a degree or a master, then the doctors may listen to that. If normal nurses without any of post basic or degree or master, it might not be working. It might be different when the palliative ward is opened. At that time, the nurse manager who runs the ward will have post-basic of palliative care, degree, or even a master, and they can have a discussion with the doctors either the patient can be discharged or not .." (P10) 


\section{Discussion}

The results are discussed concerning this study's conceptual framework of Peaceful End of Life Theory by Cornelia M. This theory helps the researcher know more about palliative care services in a wide variety of healthcare providers within two countries, Indonesia and Malaysia.

The specific objectives of this study can be related to the two major components of the theory. The first specific objectives are to explore the differences perspectives of palliative care decision making between the palliative patients and family in Indonesia and Malaysia, which had been reflected in the View of Palliative Care theme through the first component that is the major concept (not being in pain, the experience of comfort, experience of dignity/respect, being at peace, and closeness to significant others/ persons who care). Meanwhile, the second specific objectives are to explore the nursing roles in preparing the palliative patients and family in decision making of palliative care plan in Indonesia and Malaysia, which had been reflected in the Nursing Play Supportive Role theme through the relational statements of the theory that addresses the technical aspect of care, communication, psychological aspect, dignity, and respect. However, the third theme, Limitation of Resources, is not reflected from any of the components as it described the shortness of the palliative care services for both countries. These relations showed that there was no gap between the theory and the empirical evidence.

According to Schroeder and Lorenz, nurses representing the largest group in the healthcare providers can ensure the care will be delivered safely and effectively to the patients. This study confirmed that nurses are an essential factor for patients to receive care effectively and efficiently [22]. The theme that had been emerged from the data about nurses' roles is discussed in this chapter.

The nurse-patient relationship is the key to success in delivering care. The trust and respect built within this relationship can also be therapeutic for the patients and family [23]. This study confirmed that patients could trust nurses with care. Nurses were very thorough in examining and observing the patients while listening to any of the patient's complaints. It showed how compassionate nurses were to help and provide relief and support to the patients and family [24]. All the findings will be reported to the doctors for further management. If the findings are wrong, wrong management will be provided [25]. Therefore, nurses' assessment skills are crucial as the care provider for the patients and family because of nurses responsible for preventing the patients from any pain and suffering, promoting comfort, and encouraging them to live their end of life meaningfully and peacefully [26]. Therefore, the decision-making process will become easier.

Other than that, in nurses-patient relationships, nurses also are the educator who is responsible for educating and providing any of the information required by the patients. The truth about themselves is one of the patients' rights. The education includes the patients' condition, updates of all the examinations taken, and how to take care of themselves at home. The patients and family preferred nurses to re-explain and re-educate them after doctors' explanation because nurses' explanation was simpler and easier to understand [27], [28]. Thus, the patients and family will able to make decisions wiser.

Nurses are always being related to a facilitator who makes any of the protocol or procedure easier. Nurses are the best facilitator that may lead the patients and family to end of life easier. They help facilitate the patients and family on how to handle the bad news better by creating time-space and showing empathy and support for them [28]. When nurses facilitated them while they were in the grieving stage, they could get through it faster and feel comfortable, which is very important for decision making. Then, nurses could facilitate them in the decision-making process by hinting about the patient's final hours to the family and selecting a proper negotiator in the family because delaying in the decision making can increase the problems of the patients' emotional and spiritual status [16], [29].

Nurses' roles as advocators for the patients and family are usually being appreciated as they support the patients and family while recommending and encouraging them always to spend time together, enjoy the life, and if there are any problems, seeking help. These could help them to have a good quality end of life as they spent them meaningfully and peacefully [30]. According to Nsiah, Akwa, and Ninnoni, nurses are fit to be patients' advocator as they are very close to the patients because advocacy is about ensuring the quality of care received by the patients are good, and all the patients' rights are being protected while minimizing the burden on the healthcare system [31]. Therefore, nurses as advocators can help integrate the communication between the doctors, patients, and family for the decision making, so the result benefits all of them [32].

To have a good connection with the doctor, nurses need to have a good relationship with the doctors, which have been discussed in decades. It is a meaningful relationship, but it will always come second when patients involved. Therefore, the nurse-doctor relationship is one of the factors that can lead to the success of patients' care management [33].

Therefore, in the nurse-doctor relationship, there is a word of teamwork. Nurses and doctors need to work as a team to plan and deliver care for the 
patients and family effectively and efficiently. According to Siedlecki and Hixson, nurses and doctors perceive their work differently, which is where the teamwork begins to get swayed [33]. Thus, respecting each other can produce a positive and healthy working environment, which affects the patients' outcomes indirectly as it has a positive interaction with the nursepatient relationship [34], [35].

In this study, nurses played supportive roles to the doctors to ensure that every care management delivered was effective for patients to feel comfortable. Nurses acted as informants, coordinators, advisors, and executors. Within these characters that had been shown, they need good communication for the good quality of care [36], [37].

Accordingly, nurses play the role by supporting the doctors through providing the updated information and any complaints received from the patients to the doctors. Doctors need detail about the patients and family before planning the appropriate care for them. Nevertheless, it is impossible for doctors to accompany the patients $24 \mathrm{~h}$ so that doctors need the nurses to be their eyes and ears [38]. Thus, nurses can be essential informants for the doctors. According to Kurhila and Lehtimaja, transferring the information, especially the vital signs and test results, shows their competency because it needs linguistic-interactional choices, which involve the care and medical expertise [39]. Thus, doctors can make decisions faster with the proper information given by nurses [40].

Then, to ensure the teamwork is a success, nurses can act as a coordinator to integrate the patients and family with other healthcare providers [27]. Abu-Ghori et al. stated that nurses have the skill to coordinate and organize all the available hospital resources effectively, according to doctors, patients, and family needs [24]. It showed how nurses ensured all the members of the palliative care team received the same information correctly and efficiently. According to Watson, as a coordinator, one of the nurses' responsibilities is to maintain the momentum of the care pathway, especially when multiple care pathways are involved; because each of the care had their own completion time [41]. Most of the care will involve the patients and family to know what had and will happen to them. Thus, the decision-making process will become easier.

When this study's data emerged, the nurses acted as advisors for the doctors, it did not mean nurses became the top of the healthcare hierarchy, but it was referred to as the teamwork that happens during delivering the patients' care. It is all about patient-centered care so that the discussion among the healthcare providers is essentials to plan the best plan of care management for the patients [42]. Kalocsai et al. also said that nurses and doctors exchanging information, which means having a discussion about planning for the patients' care management, could build

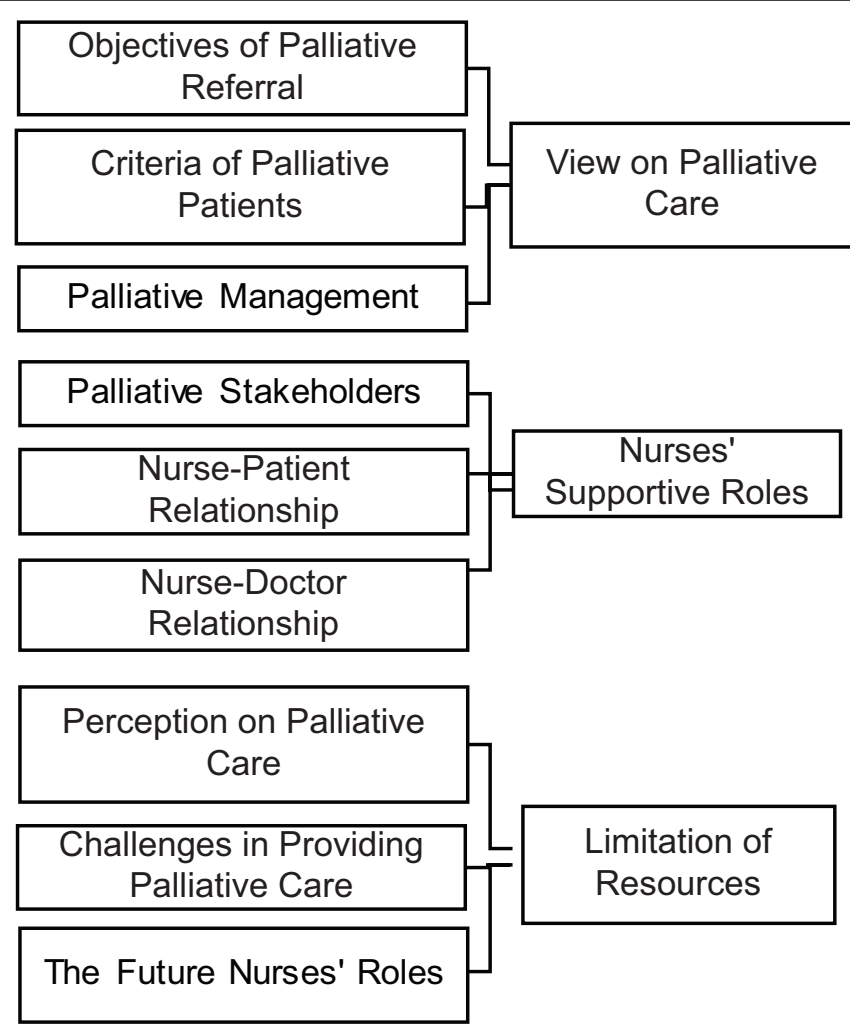

Figure 1: The summary graph of the sub-themes and themes

a positive relationship with the patients and family [27]. Furthermore, nurses and doctors have a different view of the same problems [43]. It is the advantage as the care will be planned from the multiple views, which is the best for the patients.

Then, when the care plan for the patients was completed, this is the time to accomplish the goals of care. Usually, nurses are the ones who execute all the planned care management as what had been emerged from the data. Nurses have been polishing their skills since school to care for the patients as it is one of the core abilities of a nurse [44]. Therefore, nurses are responsible for clinical tasks, such as changing wound dressing, inserting Ryles tube, inserting cannabidiol, feeding, and many more of the skills that correspond to the patients' and family's needs based on the doctor's order. Nurses' competency in their skills development by the time of their working years as the freshly graduate nurses are weak in terms of their clinical competency compared to the senior nurses [45]. Therefore, in handling the patients with life-threatening illnesses, the nurses who have more experience should lead the care while mentoring the new nurses, especially to prepare for the decision-making process [46].

\section{Conclusion}

Nurses play the supportive role in ensuring the care delivered to the patients and family are effective 
and efficient by 1) taking care the patients and family, 2) educating them on all the information regarding themselves and the therapy that will be provided to them and their side effects, 3) facilitating them in practicing their religious belief and decision making, 4) advocating them to have their rights while encouraging them to have a more meaningful and peaceful end of life, 5) informing all their updated information to doctors for further care management, 6) coordinating them with other healthcare providers, 7) giving suggestion to doctors in the discussion about the patients' care management, and 8) obeying all the care plan for the patients with confidence and competency. Thus, the patients and family can choose their decision wisely.

Knowledge is the key to success and confidence. Therefore, nurses should always improve their knowledge and skills. Therefore, they can have the competency in having discussions with physicians in planning the care for the patients. Then, physicians and other healthcare professionals will have more trust in nurses in planning and caring for the patients. By being knowledgeable about the patient's diseases and conditions, nurses can easily educate and motivate patients and family, especially the palliative patients, which is challenging.

\section{Acknowledgments}

We wish to thank all participants from both countries, Indonesia and Malaysia. We would like to thank UMY for the research funding, and we are also very grateful for the excellent cooperation between the Master of Nursing UMY and Kulliyyah of Nursing IIUM Malaysia.

\section{References}

1. World Health Organization. Noncommunicable Disease. Geneva: World Health Organization; 2018. Available from: https:// www.who.int/news-room/fact-sheets/detail/noncommunicablediseases. [Last accessed on 2020 Nov 04].

2. Abajobir AA, Abbafati C, Abbas KM, Abd-Allah F, Abera SF Aboyans $\mathrm{V}$, et al. Global, regional, and national age-sex specific mortality for 264 causes of death, 1980-2016: A systematic analysis for the global burden of disease study 2016. Lancet. 2017;390(10100):1151-210.

PMid:28919116

3. Connor SR, Bermedo MC. Global Atlas of Palliative Care at the End of Life. Geneva: World Health Organization; 2014.

4. Ministry of Health. Annual Report Ministry of Health 2011. Saudi Arabia: Ministry of Health; 2011. p. 351. https://doi.org/10.21474/ ijar01/2586

5. World Health Organization. Definition of Palliative Care. Geneva: World Health Organization; 2015. Available from: http://www. who.int/cancer/palliative/definition/en. [Last accessed on 2020 Jan 14]

6. Budijanto D, HardhanaB, YudiantoM, SoenardiT.ProfilKesehatan Indonesia 2016. Kementerian Kesehatan Republik Indonesia; 2017. Available from: http://www.depkes.go.id/resources/ download/pusdatin/lain-lain/datadaninformasikesehatan profil kesehatan indonesia 2016-smaller size-web.pdf. https://doi. org/10.31219/osf.io/hwxsa. [Last accessed on 2020 Jun 04].

7. Lim R. ED02.04 palliative care in South-East Asia. J Thorac Oncol. 2017;12(1):S24.

8. Docherty SL, Thaxton C, Allison C, Barfield RC, Tamburro RF. The nursing Dimension of providing palliative care to children and Adolescents with cancer. Clin Med Insights Pediatr. 2012;6:75-88. https://doi.org/10.4137/cmped.s8208 PMid:23641169

9. Visser M, Deliens L, Houttekier D. Physician-related barriers to communication and patient-and family-centred decisionmaking towards the end of life in intensive care: A systematic review. Crit Care. 2014;18(6):604. https://doi.org/10.1186/ s13054-014-0604-z PMid:25403291

10. McDonald J, Swami N, Hannon B, Lo C, Pope A, Oza A, et al. Impact of early palliative care on caregivers of patients with advanced cancer: Cluster randomised trial. Ann Oncol. 2015;1(416):163-8. https://doi.org/10.1093/annonc/mdw438 PMid:27687308

11. Zimmermann C, Swami N, Krzyzanowska M, Hannon B, Leighl N, Oza A, et al. Early palliative care for patients with advanced cancer: A cluster-randomised controlled trial. Lancet. 2014;383(9930):1721-30. https://doi.org/10.1016/ s0140-6736(13)62416-2 PMid:24559581

12. Patel $K$, Masi $D$. Palliative care in the era of health care reform. Clin Geriatr Med. 2015;31(2);265-70. PMid:25920061

13. Attia AK, Abd-Elaziz WW, Kandeel NA. Critical care nurses' perception of barriers and supportive behaviors in end-of-life care. Am J Hosp Palliat Med. 2013;30(3):297-304. https://doi. org/10.1177/1049909112450067 PMid:22743231

14. Gramling R, Sanders M, Ladwig S, Norton SA, Epstein R, Alexander SC. Goal communication in palliative care decisionmaking consultations. J Pain Symptom Manag. 2015;50(5):7016. https://doi.org/10.1016/j.jpainsymman.2015.05.007 PMid:26025274

15. Caprio AJ. Palliative care: Renaming as supportive care and integration into comprehensive cancer care. CMAJ. 2016;188(10):711-2. https://doi.org/10.1503/cmaj.160206 PMid:27091796

16. Adams JA, Anderson RA, Docherty SL, Tulsky JA, Steinhauser KE, Bailey DE. Nursing strategies to support family members of ICU patients at high risk of dying. Heart Lung. 2014;43(5):40615. https://doi.org/10.1016/j.hrtlng.2014.02.001 PMid:24655938

17. BroomA, Kirby E, Good P, Wootton J, Yates P, Hardy J. Negotiating futility, managing emotions. Qual Health Res. 2015;25(3):299309. https://doi.org/10.1177/1049732314553123 PMid:25246331

18. Kirby E, Broom A, Good P. The role and significance of nurses in managing transitions to palliative care: A qualitative study. BMJ Open. 2014;4(9):e006026. https://doi.org/10.1136/ bmjopen-2014-006026

PMid:25270859

19. Beng TS, Chin LE, Guan NC, Ann YH, Wu C, Kuan WS, et al. The 
experiences of well-being of palliative care patients in Malaysia: A thematic analysis. Am J Hosp Palliat Med. 2015;32(5):490503. https://doi.org/10.1177/1049909114523829 PMid:24574364

20. Effendy C, Vissers K, Tejawinata S, Vernooij-Dassen M, Engels $Y$. Dealing with symptoms and issues of hospitalized patients with cancer in Indonesia: The role of families, nurses, and physicians. Pain Pract. 2015;15(5):441-6. https://doi. org/10.1111/papr.12203

PMid:24799294

21. Ruland CM, Moore SM. Theory construction based on standards of care: A proposed theory of the peaceful end of life. Nurs Outlook. 1998;46(4):169-75. https://doi.org/10.1016/ s0029-6554(98)90069-0

PMid:9739534

22. Schroeder K, Lorenz K. Nursing and the future of palliative care. Asia Pac J Oncol Nurs. 2018;5:4-8. PMid:29379825

23. Leslie JL, Lonneman W. Promoting trust in the registered nurse patient relationship. Home Healthc Now. 2016;34(1):38-42. https://doi.org/10.1097/nhh.0000000000000322 PMid:26645843

24. Abu-Ghori IK, Bodrick MM, Hussain R, Rassool GH. Nurses involvement in end-of-life care of patients after a do not resuscitate decision on general medical units in Saudi Arabia. Intens Crit Care Nurs. 2016;33:21-9. https://doi.org/10.1016/j. iccn.2015.10.002

PMid:26685090

25. Kusi-Appiah E, Dahlke S, Stahlke S. Nursing care providers perceptions on their role contributions in patient care: An integrative review. J Clin Nurs. 2018;27(21-22):3830-45. https:// doi.org/10.1111/jocn.14534

PMid:29777552

26. Donelan K, Chang Y, Abebe JB, Spetz J, Auerbach DI, Norman L, et al. Care management for older adults: The roles of nurses, social workers, and physicians. Health Affairs. 2019;38(6):9419. https://doi.org/10.1377/hlthaff.2019.00030 PMid:31158015

27. Kalocsai C, Amaral A, Piquette D, Walter G, Dev SP, Taylor P, et al. It's better to have three brains working instead of one: A qualitative study of building therapeutic alliance with family members of critically ill patients. BMC Health Serv Res. 2018;18(1):533. https://doi.org/10.1186/s12913-018-3341-1 PMid:29986722

28. Pecanac K, King B. Nurse family communication during and after family meetings in the intensive care unit. J Nurs Scholarsh. 2019;51(2):129-37. https://doi.org/10.1111/jnu.12459 PMid:30697910

29. Odachi R, Tamaki T, Ito M, Okita T, Kitamura Y, Sobue T. Nurses' experiences of end-of-life care in long-term-care hospitals in japan: balancing improving the quality of life and sustaining the lives of patients dying at hospitals. Asian Nurs Res. 2017;11(3):207-215. https://doi.org/10.1016/j.anr.2017.08.004

30. Gerber L. Understanding the nurse's role as a patient advocate. New Horizon. 2018;48(4):55-8. PMid:29561371

31. Nsiah C, Siakwa M, Ninnoni JP. Registered nurses' description of patient advocacy in the clinical setting. Nursing Open. 2019;6(3):1124-32. https://doi.org/10.1002/nop2.307

PMid:31367438
32. Wai J, Tse K, Shuk M, Hung Y, Mei S, Pang C. End of life care in Hongkong. J Emerg Nurs. 2016;42(3):224-32. PMid:27033338

33. Siedlecki SL, Hixson ED. Relationships between nurses and physicians matter. Online J Issues Nurs. 2015;20(3):6. PMid:26882515

34. Elsous A, Radwan M, Mohsen S. Nurses and physicians attitudes toward nurse-physician collaboration: A survey from gaza strip, palestine. Nurs Res Pract. 2017;2017:7406278. https://doi.org/10.1155/2017/7406278 PMid:28326194

35. Henkin S, Chon TY, Christopherson ML, Halvorsen AJ, Worden LM, Ratelle JT. Improving nurse-physician teamwork through interprofessional bedside rounding. J Multidiscip Healthc. 2016;9:201-5. https://doi.org/10.2147/jmdh.s106644 PMid:27194915

36. Amudha $\mathrm{P}$, Hamidah $\mathrm{H}$, Annamma $\mathrm{K}$, Ananth $\mathrm{N}$. Effective communication between nurses and doctors: Barriers as perceived by nurses. J Nurs Care. 2018;7:3. doi:10.4172/2167-1168.1000455.

37. Wang YY, Wan QQ, Lin F, Zhou WJ, Shang SM. Interventions to improve communication between nurses and physicians in the intensive care unit: An integrative literature review. Int $\mathrm{J}$ Nurs Sci. 2018;5(1):81-8. https://doi.org/10.1016/j.jijnss.2017.09.007

38. Cipriano PF. The nation's 3.4 million registered nurses a force for health. MHealth. 2016;2:9. https://doi.org/10.21037/ mhealth.2016.03.04

PMid:28293587

39. Kurhila S, Lehtimaja I. Dealing with numbers: Nurses informing doctors and patients about test results. Discourse Stud. 2019;21(2):180-98. https://doi.org/10.1177/1461445618802662

40. Caronia L, Saglietti M, Chieregato A. Challenging the interprofessional epistemic boundaries: The practices ofinforming in nurse-physician interaction. Soc Sci Med. 2020;246:112732. https://doi.org/10.1016/j.socscimed.2019.112732

41. Watson DJ. The role of the nurse coordinator in the enhanced recovery after surgery program. Nursing. 2017;47(9):13-7. https://doi.org/10.1097/01.nurse.0000522018.00182.c7 PMid:28834927

42. Kuven BM, Giske T. Interaction between nurses and doctors is important for the nutritional status of nursing home patients. Fagfellevurdert Res. 2017;2017:64510. https://doi.org/10.4220/ sykepleienf.2017.64510en

43. McAndrew NS. Nurses and physicians bring different perspectives to end-of-life decisions in intensive care units. Evid Based Nurs. 2018;21(3):85. https://doi.org/10.1136/ eb-2018-102902

PMid:29735723

44. Fukada M. CNCSS, clinical nursing competence self-assess-ment scale nursing competency: Definition, structure and development. Yonago Acta Medica. 2018;61:1-7. doi:10.4172/21671168.1000455. https://doi.org/10.33160/yam.2018.03.001

45. Karami A, Farokhzadian J, Foroughameri G. Nurses' professional competency and organizational commitment: Is it important for human resource management? 2017;12(11):e0187863. https:// doi.org/10.1371/journal.pone.0187863

PMid:29117271

46. Langins M, Borgermans L. Strengthening a competent health workforce for the provision of coordinated/ integrated health services. Int J Integr Care. 2016;16(6):A231. https://doi. org/10.5334/ijic. 2779 